\title{
Complications among Mothers and New Born Due to Delivery Process in Rupandehi District Nepal
}

Shanta Sharma, ${ }^{1}$ Indra Dhakal $^{2}$

'Department of Community Medicine, Devdaha Medical College and Research Institute, Kathmandu University, Rupandehi, Nepal. 'Department of Orthopedics, Lumbini Zonal Hospital, Butwal, Rupandehi, Nepal.

\section{ABSTRACT}

Background: Child birth is a universally celebrated occasion, yet everyday for thousands of women child birth is
experienced not as a joyful event as it should be, but as a private hell that may even end in death. The objective of
this study is to determine the complications of normal delivery and cesarean section on the mothers and new born.
Methods: A descriptive study was conducted in two selected hospitals of Rupandehi district, Nepal. Data was
collected as per pretested structured proforma from 550 respondents who were the mothers and new born delivered
normally and through cesarean section randomly till the completion of sample size and analyzed by using SPSS,
MANOVA and Chi-square test to determine associations between categorical variables.
Results: In a total of 550 deliveries, $25.8 \%$ were cesarean delivery, $42.7 \%$ motherssuffered from delivery related
complications, common were PPH (21.1\%), prolonged labour $(8.5 \%)$ and wound infection $(7.6 \%)$. $35.5 \%$ of
newborn had complications, common were respiratory distress $(6.3 \%)$ and neonatal jaundice $(4.2 \%)$.
Conclusions: Delivery related complications were higher among Lower segment cesarean section compared to
vaginal delivery in mothers and newborn.
Keywords: Cesarean section; child birth; maternal complication; new born; vaginal delivery.

\section{INTRODUCTION}

Globally, $80 \%$ of maternal deaths are due to direct obstetric complication, $61 \%$ of which occur in the postpartum period, more than half of which take place during delivery or within 1 day of delivery. About $17 \%$ of maternal death happens during child birth itself. This can be attributed to pregnancy related complication occurring throughout the pregnancy, labour, childbirth and in the postpartum period. Current estimates indicate that only $56 \%$ of deliveries receive care. In developing countries complication of delivery and child birth are leading causes of death. Every year, almost 8 million still births and early neonatal deaths occur. ${ }^{1}$

Complications of delivery process are one of the leading causes of maternal and neonatal mortality and morbidity in Nepal. Such problems can be reduced through proper care during delivery process to the mother as well as new born. ${ }^{2,3}$ So our study aimed to compare maternal and fetal complication associated with types of delivery process.

DOI: $\underline{\text { http: } / / \mathrm{dx} \text {.doi.org/10.3126/ }}$

inhrc.v16i2.20309

\section{METHODS}

A descriptive study was conducted in Rupandehi district, Nepal. Rupandehi District was selected purposively because Rupandehi District is one of the terai districts where most of the delivery occurs. There are 18 Hospitals in Rupandehi district where delivery services are offered. ${ }^{4}$ Purposively, 2 hospitals were selected. They are Lumbini zonal hospital (Government) and Siddhartha children and women hospital (Private Mission Hospital). Mothers and new born delivered through normal delivery and caesarean section in selected hospitals were study unit. Data was collected as per pretested structured performa from 550 respondents randomly till the completion of sample size. A set of structured pretested schedule was used for data collection. Data was collected through direct interview by the researcher with the help of schedule and was analyzed using SPSS, Manova and Chi square test to determine association between categorical variables. 
Complications among Mothers and New Born Due to Delivery Process

Ethical approval was taken from Sam Higginbottom Institute of Agriculture, Technology \& Sciences, institutional ethical committee for biomedical Research on Human Participants, SHIATS, Allahabad, and Nepal health research council (NHRC) Kathmandu, Nepal. Authorities of Selected Hospitals and Respondents were fully informed about objectives of study and verbal consent was taken before data collection.

\section{RESULTS}

In a total of 550 deliveries, majority of respondents belonged to age group 25-29 (37.6\%), followed by age group $20-24$ years $(29.1 \%)$, age group $30-34$ years (26.9\%), $4.5 \%$ were above 35 years age and $1.8 \%$ was below 19 years age.

Table 1. shows that majority of respondents had vaginal mode of delivery.

Table 1. Mode of delivery of the respondent.
\begin{tabular}{lrr} 
Mode of delivery & Frequency & Percentage \\
\hline Vaginal & 408 & 74.20 \\
LSCS & 142 & 25.80 \\
Total & 550 & 100.00 \\
\hline
\end{tabular}

Table 2. Shows that majority of respondents has postpartum hemorrhage followed by prolonged labor and wound infection.

\begin{tabular}{|lr}
\hline Table2. Maternal complications. \\
\hline Maternal Complications & (Total - 236 mothers) \\
Percentage
\end{tabular}

Table3. shows that common new born complication was low birth weight followed by fetal distress and neonatal jaundice.
Table 3. Newborn Complications.

\begin{tabular}{lr} 
Neonatal Complications & Percentage \\
\hline Birth injury & 2.20 \\
\hline Meconium aspiration. & 1.80 \\
\hline Cord prolapsed & 0.60 \\
\hline Fetal distress & 6.20 \\
Eye infection & 0.50 \\
Neonatal jaundice & 4.20 \\
Low apgar score & 2.70 \\
\hline Cephalic hematoma & 0.90 \\
Low birth weight & 7.40 \\
\hline Congenital anomaly & 0.90 \\
Preterm & 1.10 \\
Neonatal death & 3.80 \\
Respiratory distress & 6.30 \\
\hline
\end{tabular}

Table4. shows that there is association between maternal complications and mode of delivery. Maternal comlpications are higher in LSCS.

Table 4.Association between Mode of delivery and maternal complications.

\begin{tabular}{lrrr}
$\begin{array}{l}\text { Mode of } \\
\text { delivery }\end{array}$ & \multicolumn{2}{c}{ Maternal complication } & Total (550) \\
\hline Vaginal & $28.9 \%$ & $45.3 \%$ & $74.2 \%(408)$ \\
LSCS & $13.8 \%$ & $12.0 \%$ & $25.8 \%(142)$ \\
Total & $42.7 \%$ & $57.3 \%$ & $100.0 \%$ \\
\hline
\end{tabular}

$(x 2=9.11$, Level of significance $=0.05 \%$ for $1 d f, \quad P<0.05$

Significant)

Table 5. shows that there is association between neonatal complications and mode of delivery. Neonatal complications are higher in LSCS.

Table 5. Association between Mode of Delivery and Neonatal Complications.

Mode of Neonatal complication

delivery Present (190) Absent (360) Total (550)

\begin{tabular}{cccc}
\hline Vaginal & $21.1 \%$ & $53.1 \%$ & $74.2 \%$ \\
LSCS & $13.5 \%$ & $12.4 \%$ & $25.8 \%$ \\
Total & $34.5 \%$ & $65.5 \%$ & $100.0 \%$
\end{tabular}

$(x 2=26.12$, Level of significance $=0.05 \%$ for $1 \mathrm{df}, \mathrm{P}<0.05$ significant)

\section{DISCUSSION}

This study reveals that majority of respondents were from 20 to 30 years of age (66.7\%). This may be because most of people marry around this age and also 
this is the most fertile phase of women's life. Nepal demographic-and health survey (2016) shows that there was a significant raise in median age for getting marriage amongst girls during the last 15 years, from 16.4 years in 1996 to 17.9 years in 2016 . This is another clear indication of a continuing shift to later marriage in Nepal. The proportion of women age 15-19 who were married by age 15 declined by 10 percentage points from 1996 (14\%) to $2016(4 \%) .^{5}$

Majority of respondents had vaginal mode of delivery $74.20 \%$ followed by LSCS $25.80 \%$. Similar study reported that total number of deliveries during the period was 1632, out of them 411 deliveries were by cesarean section thereby making a lower segment cesarean section rate of $25.18 \% .{ }^{6}$ Our results are consistent with previous studies which shows similar rates of LSCS and the recent rise in LSCS rate has became a worldwide phenomenon. ${ }^{7}$ Lower segment caesarian segment rate in U.S.A has increased to 29.1\%, England 21.5 percent, and in Latin American nations 40\%. ${ }^{7}$ Nine countries participated in the Asia global survey: Cambodia, China, India, Japan, Nepal, Philippines, Sri Lanka, Thailand, and Vietnam. Obtained data for 1,09,101 of 1,12,152 deliveries reported in 122 recruited facilities ( 97 percent coverage), and analyzed 1,07,950 deliveries. The overall rate of caesarean section was $27 \cdot 3 \%(n=29,428) .{ }^{8}$

Furthermore, the common maternal complication were postpartum hemorrhage (116 deliveries, $21.1 \%$ ), prolonged labor (47 deliveries, 8.5\%) followed by wound infection (42 deliveries, 7.6\%). Similar study on total population of $3,298,319$, comprising $12 \%$ of Nepal population showed that pregnancy and deliveryrelated causes are amongst the top ten reasons for MM in Nepal. The main direct cause, hemorrhage has been dramatically reduced, down from $41 \%$ in 1998 to $24 \%$ in $2006 .{ }^{5}$ In India, post partum hemorrhage (25.6\%) ranks first as the cause of maternal death, followed by prolong labour (6.2\%). ${ }^{9} \mathrm{~A}$ study was undertaken in the department of Obstetrics and Gynecology at Kasturba hospital, Delhi. In total of 100 deliveries, it was found that $8 \%$ of patients developed post-partum hemorrhage (6\% in vaginal and $2 \%$ in cesarean group). ${ }^{10}$

Another major complication was prolonged labor (8.5\%) which is similar to the study showed that approximately $8 \%$ of all pregnant mothers did suffer from prolonged labour. ${ }^{11}$ Another prospective study carried out in Mymensing Medical College Hospital, Department of Obs and Gynae from January 1996 to March 1996. In total 100 patients, prolong labour was present in $10.0 \%$ and Wound infection in $11.0 \%$, which is similar to this study. ${ }^{12}$
Similarly, retrospective study which included 1632 patients delivered by LSCS at GMERS Medical College, sola between June 2013 to December 2013, out of which 411 delivered by LSCS thereby making a LSCS rate of $25.18 \%$, and prolong labour included $10.94 \%$ of deliveries. ${ }^{13}$

Study also noted that wound or postpartum infection was $7.6 \%$ and the similar study found that $5.5 \%$ of vaginal normal deliveries and $7.4 \%$ of abdominal deliveries were complicated with postpartum infection. ${ }^{14}$ Similar study shows that wound infection were present in $9 \%$ of deliveries (cesarean delivery $6 \%$ and vaginal delivery $3 \%) .{ }^{10}$ Current literature reviews have shown that post operative infection can be up to $30 \%$ following an LSCS. At Hornsby Ku-ring-gai Hospital baseline data for women undergoing LSCS found that post-operative infection were as high as $20 \% .^{15}$

Majority of newborn complication were low birth weight (40 newborn, 7.4\%), respiratory distress (35 newborn, 6.3\%) and neonatal jaundice (23 newborn, 4.2\%). A study performed by the Agency for Healthcare Research and Quality (2011) showed that out of total 3.8 million births in the U.S.A. in 2011, approximately $6.1 \%$ were diagnosed having low birth weight. ${ }^{16}$ Similar study showed Low birth weight in 4 percent of vaginal and $8 \%$ of LSCS deliveries. ${ }^{10}$

Another common fetal complication wasrespiratory distress (6.2\%). Indian Journal of maternal Child Health (1996) mentioned that the incidence of respiratorydistress ranges from $2.2 \%$ to $7.6 \%$ in developed countries and from $0.7 \%$ to $8.3 \%$ in India. ${ }^{17}$ Another cross-sectional retrospective study, conducted between January 1995 and December 1998, all patients consecutively admitted for Deliveries at Hospital Israelita Albert Einstein HIAE) were included in study. A total of 8,457 medical records were analyzed, respiratory distress occurred in 260 (3.5\% of total). Of these, $200(2.7 \%)$ were born by C-section. ${ }^{18}$

In this study, Jaundice was present in $4.2 \%$ of neonates. Similar study in the Cama and Albless hospital, a tertiary care center located in South Mumbai, which cares for over 3000 deliveries per year, showed that percentages of babies admitted in NICU for jaundice were $6.9 \% .^{19}$ Another study including all babies born at Nehru Hospital, Postgraduate Institute of Medical Education and Research, Chandigarh between April 1994 and June 1995, 6.5\% babies admitted to the newborn unit were with a diagnosis of neonatal jaundice. ${ }^{20}$ Similar study showed that out of a total 7680 live births,454(5.9\%) developed neonatal jaundice. ${ }^{21}$ 
Complications among Mothers and New Born Due to Delivery Process

This study shows that maternal and newborn complications were significantly associated with mode of delivery and was considerably high in LSCS compared to vaginal delivery. Similar study showed that risk of maternal mortality and morbidity is increased for caesarean section as compared to vaginal delivery. ${ }^{22}$ In similar study caesarean section in developing countries is associated with significant increase in maternal morbidity. ${ }^{23}$ Similarly, a six months prospective, observational study was conducted, including 320 Patients, maternal morbidity was noted in $12.76 \%$ of the patients who had a Cesarean section and in only $2.74 \%$ of patients who had vaginal delivery. ${ }^{24}$

\section{CONCLUSIONS}

Approximately half of the mother suffered from delivery related complications $(42.7 \%)$, common were $\mathrm{PPH}$ (21.1\%), prolonged labour $(8.5 \%)$ and wound infection (7.6\%). One third newborn had complications (34.5\%) and the common were low-birth-weight $(7.4 \%)$, respiratory distress $(6.3 \%)$ and neonatal jaundice (4.2\%). Maternal and newborn complications were significantly associated with mode of delivery and were considerably high in LSCS compared to vaginal delivery.

\section{ACKNOWLEDGEMENTS}

We would like to acknowledge all the respondents for their kind cooperation during this study. We are grateful to all the members of Faculty of Health Sciences, Sam Higginbottom University of Agriculture, Technology and Sciences, Allahabad, India for their academic guidance and support.

\section{REFERENCES}

1. Zahr CA, Wardlaw TM, Choi Y. Maternal mortality in 2000: estimates developed by WHO, UNICEF and UNFPA. World Health Organization; 2004.

2. K.Park, Text Book of Preventive and Social Mdicine, $18^{\text {th }}$ Edition, M/S Banarsidas Bhanot Publication, 2004; 364 367

3. Shrestha R. Maternal mortality in nepal: addressing the issue. Inquiries Journal. 2012;4(10).[Full Text]

4. Regmi LR. Lumbini zonal hospital. lzhospital.gov.np.

5. Ministry of Health, Nepal; New ERA; and ICF. 2017. Nepal Demographic and Health Survey 2016; 75-150
6. Nikhil A. Analysis of Trends in LSCS Rate and Indications of LSCS-A Study in a Medical College Hospital GMERS, Sola, Ahmedabad. International Journal of Pharmacy \& Bio-Sciences. 2015 Jan 15;2(1).[Full Text]

7. Kamilya G, Seal SL, Mukherji J, Bhattacharyya SK, Hazra A. Maternal mortality and cesarean section delivery: An analytical observational study. J Obstet Gynecol Res. 2010 April; 36(2): 248-253.[DOI]

8. Lumbiganon P, Laopaiboon M, Gülmezoglu AM, Souza JP, Taneepanichskul S, Ruyan P, et al. Method of delivery and pregnancy outcomes in Asia: the WHO global survey on maternal and perinatal health 2007-08. The Lancet. 2010 Feb 6;375(9713):490-9.[DOI]

9. Arora P. Maternal mortality-Indian scenario. Med J Armed Forces India. 2005 Jul;61(3):214.[DOI]

10. Latika GK, Hooda R, Singh S. Study of comparison of maternal and fetal outcome of elective repeat caesarean versus vaginal birth in women after one prior lower segment caesarean section. Int J Reprod Contracept Obstet Gynecol. 2015;4(3):664-8.[DOI]

11. Nystedt A, Hildingsson I. Diverse definitions of prolonged labour and its consequences with sometimes subsequent inappropriate treatment. BMC Pregnancy Childbirth. 2014 Dec;14(1):233.

12. Nahar K. Indications of Caesarean Section-Study of 100 cases in Mymensingh Medical College Hospital. Journal of Shaheed Suhrawardy Medical College. 2012 Oct 14;1(1):6-10.[DOI]

13. Nikhil A. Analysis of Trends in LSCS Rate and Indications of LSCS-A Study in a Medical College Hospital GMERS, Sola, Ahmedabad. International Journal of Pharmacy \& Bio-Sciences. 2015 Jan 15;2(1).[Full Text]

14. Yokoe DS, Christiansen CL, Johnson R, Sands KE, Livingston J, Shtatland ES, Platt R. Epidemiology of and surveillance for postpartum infections. Emerging infectious diseases. $2001 \mathrm{Sep} ; 7(5): 837$.[DOI]

15. Australian council on healthcare standards. Quality Initiatives, Entries in the 10th Annual ACHS Quality Improvement Awards; 2007. Available from: s3.amazonaws.com/zanran_storage/www.achs.org.au/ ContentPages/52011980.pdf. p.95

16. Kowlessar N.M., Jiang H.J., and Steiner C. Hospital Stays for Newborns, 2011. HCUP Statistical Brief \#163. October 2013. Agency for Healthcare Research and 
Quality, Rockville, MD

17. Kumar A, Bhat BV. Epidemiology of respiratory distress of newborns. Indian J Pediatr. 1996; 63:93-8. [PubMed]

18. Breim MC, Segre CA, Lippi UG. Morbidity in neonates according to the mode of delivery: a comparative study. Einstein (São Paulo). 2010 Sep;8(3):308-14.[DOI]

19. Katke RD, Zarariya AN, Desai PV. LSCS audit in a tertiary care center in Mumbai: to study indications and risk factors in LSCS and it's effect on early peri-natal morbidity and mortality rate. Int J Reprod Contracept Obstet Gynecol. 2017 Feb 10;3(4):963-8.[DOI]

20. Narang A, Gathwala G, Kumar P. Neonatal jaundice: an analysis of 551 cases. Indian Pediatr. 1997 May 1;34:42932.[Full Text]

21. Singhal PK, Singh M, Paul VK, Deorari AK, Ghorpade MG. Spectrum of neonatal hyperbilirubinemia: an analysis of 454 cases. Indian Pediatr. 1992 Mar 1;29(3):319-25. [Full Text]
22. Lumbiganon P, Laopaiboon M, Gülmezoglu AM, Souza JP, Taneepanichskul S, Ruyan P, Attygalle DE, Shrestha N, Mori R, Hinh ND, Bang HT. Method of delivery and pregnancy outcomes in Asia: the WHO global survey on maternal and perinatal health 2007-08. The Lancet. 2010 Feb 6;375(9713):490-9.[DOI]

23. Mac Dorman MF, Declercq E, Menacker F, Malloy MH. Infant and neonatal mortality for primary cesarean and vaginal births to women with "no indicated risk," United States, 1998-2001 birth cohorts. Birth. 2006 Sep 1;33(3):175-82.[DOI]

24. Jinturkar AA, Dongaonkar D. Study of obstetric and fetal outcome of post caesarean section pregnancy at tertiary care center. International Journal of Recent Trends in Science and Technology. 2014;10(3):530-7. 